\title{
Hydrogeochemistry and Quality Assessment of Groundwater Based on Fuzzy Analytical Hierarchy Process: A Case Study From Sulin Coal-Mining District in Northern Anhui, China
}

\author{
Huili Qiu ${ }^{1,2}$, Herong Gui'*, Pei Fang ${ }^{3}$, Guanping Li $^{3}$ \\ ${ }^{1}$ National Engineering Research Center of Coal Mine Water Hazard Control (Suzhou Universtiy), Suzhou, China \\ ${ }^{2}$ Intelligent Information Processing Laboratory, School of Information Engineering, Suzhou University, Suzhou, China \\ ${ }^{3}$ Qianyingzi Coalmine of Wanbei Coal-Electricity Group Co. Ltd, Suzhou, China
}

Received: 12 September 2020

Accepted: 11 November 2020

\begin{abstract}
Sulin coal-mining district is characterized by rich coal resources, and its shallow groundwater (SG) and mid-layer groundwater (MG) are the main freshwater source for drinking, agriculture, and industrial purpose. However, frequent mining activities had damaged groundwater systems. Therefore, it is necessary to understand the hydrogeochemical characteristics and determine the status of groundwater quality. To achieve a higher degree of accuracy in water quality assessment, this paper proposed a fuzzy analytical hierarchy process (AHP) which combined the fuzzy analysis model and AHP model. The results showed that $\mathrm{Na}^{+}$and $\mathrm{HCO}_{3}{ }^{-}$were the dominant cation and anion in both SG and $\mathrm{MG}$, respectively. In addition, TDS, $\mathrm{SO}_{4}^{2-}, \mathrm{Cl}^{-}, \mathrm{Mn}, \mathrm{Na}^{+}$, and $\mathrm{NO}_{3}^{-}$of $\mathrm{SG}$ and TDS, $\mathrm{SO}_{4}^{2-}, \mathrm{Cl}^{-}, \mathrm{Mn}$, $\mathrm{Na}^{+}$and $\mathrm{F}^{-}$of $\mathrm{MG}$ were higher than the grade III limits of Chinese groundwater standards. Analysis with molar ratios of major ions suggested that the geochemical composition of SG and MG were mainly determined by the dissolution of silicates. The fuzzy AHP evaluation results indicated that the samples of SG and MG within the III-type water accounted for $90.64 \%$ and $94.44 \%$, respectively, and their water quality was good, which were consistent with the actual natural conditions of the study area.
\end{abstract}

Keywords: water quality assessment, fuzzy analytical hierarchy process, heavy metals, hydrogeochemistry, coal-mining district

\section{Introduction}

Groundwater is an essential component of the Earth's freshwater resources and is also a major

*e-mail: guiherong@163.com water source for agricultural and domestic uses where surface water is not enough for human living [1]. The availability of groundwater is particularly crucial in mining area [2]. In recent years, with the acceleration of industrialization and urbanization in China, excessive groundwater exploitation and groundwater pollution have been common in the whole 
country [3]. Moreover, the escalating utilization of groundwater results in a decline in water levels as well as degradation of its quality. In fact, the mining areas have been subject to facing these two issues too. Due to the long-term mining of coal mines, a large number of toxic and harmful wastewater, dust, coal cinder as well as other contaminants are produced and may enter into groundwater through runoff and infiltration. Finally, the ingestion of contaminant groundwater may threaten human health $[4,5]$. Therefore, it has become increasingly necessary to understand the hydrochemical characteristics and water quality of groundwater in the mining areas.

The Sulin coal-mining district, located in the north of Anhui Province, is an important coal energy base in East China, with a long-term history of coal mining. Up to now, the study concerning hydrogeochemistry of groundwater in the study area mainly focused on surface water and deep groundwater. Surface water sampling is convenient and directly related to the supergene environment of the mining area, therefore, the research results are abundant [6,7]. Deep groundwater is the main water filling source of coal mining. In order to identify the water inrush source of coal mine and prevent water accidents, the theory and application of hydrogeochemistry in this layer are also concerned
[8-10]. However, it is possible to find a limited number of studies on both shallow groundwater and mid-layer groundwater $[11,12]$.

In the study area, shallow groundwater is mainly used for agricultural irrigation and drinking by rural residents in a few areas. Due to its proximity to the surface, the fluctuation of water levels is mainly affected by rainfall. As the main water supply source, the midlayer groundwater supply has a large scale, which leads to a decrease of groundwater level of $\mathrm{MG}$ around the mining area. As SG is seriously affected by the surface environment of the mining area, the waste caused by coal mining will directly affect the quality of SG. If SG poses a threat to the mid-layer water source, it will involve the drinking water safety of tens of millions of residents in the mining area. In view of the importance of $\mathrm{SG}$ and $\mathrm{MG}$, the present attempt has been made to understand the hydrogeochemical characteristics of SG and MG in Sulin coal-mining district, and identify the main hydrogeochemical process and formation mechanisms. Besides, this study proposed a fuzzy AHP method to evaluate water quality of SG and MG, which combined the fuzzy analysis model and AHP. This method not only solved the problem that the index with the largest weight in fuzzy method played a decisive role in the whole evaluation result, but also solved

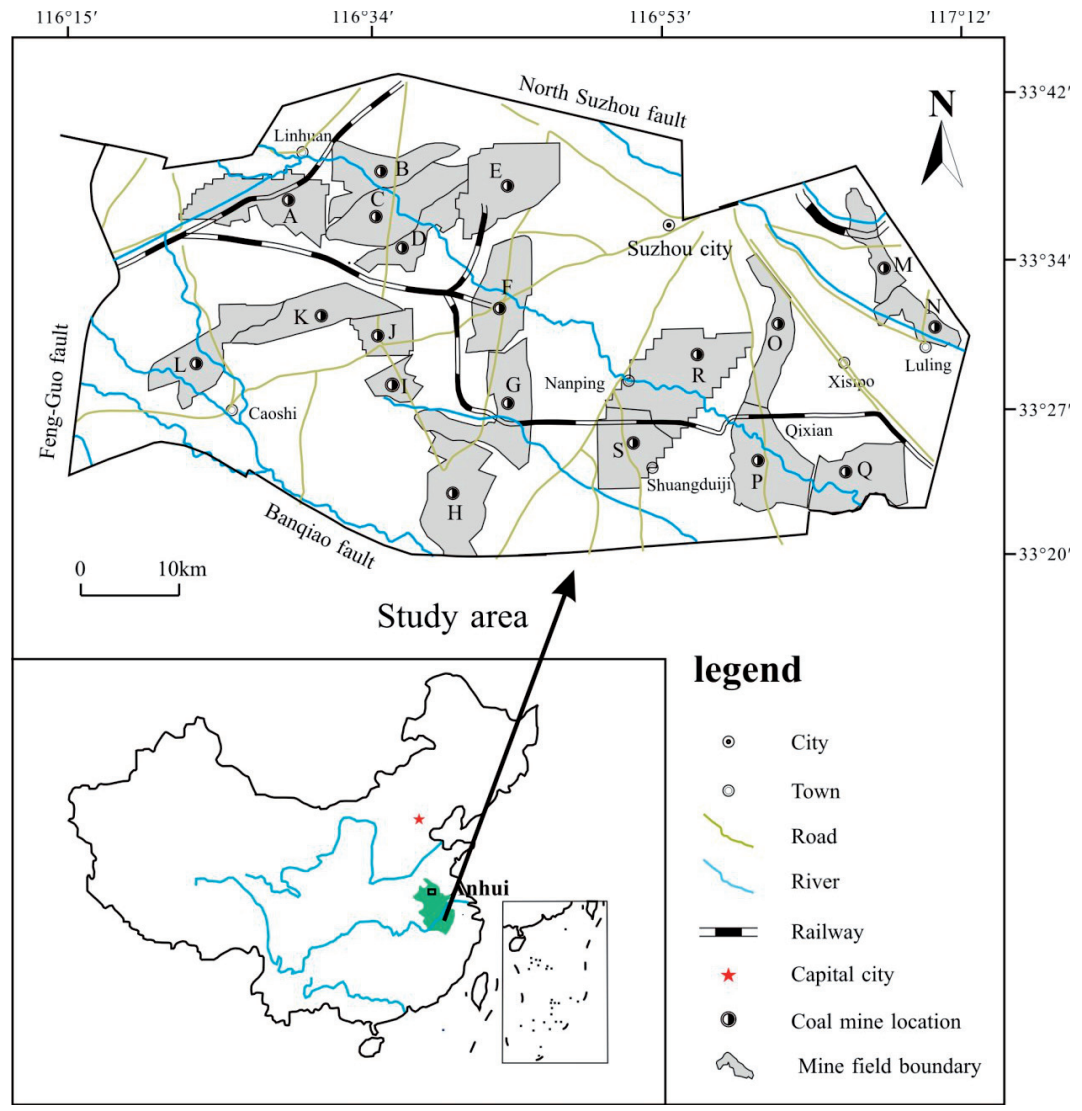

Fig. 1. Geographical location of the study area. A is Qingdong mine, B is Haizi mine, C is Linhuan mine, D is Tongting mine, E is Yangliu mine, $\mathrm{F}$ is Suntuan mine, $\mathrm{G}$ is Renlou mine, $\mathrm{H}$ is Xutuan mine, I is Jiegou mine, J is Wugou mine, $\mathrm{K}$ is Yuanyi mines, $\mathrm{L}$ is Yuaner mines, $\mathrm{M}$ is Zhuxianzhuang mine, $\mathrm{N}$ is Luling mine, $\mathrm{O}$ is Taoyuan mine, $\mathrm{P}$ is Qinan mine, $\mathrm{Q}$ is Qidong mine, $\mathrm{R}$ is Qianyingzi mine, and $\mathrm{S}$ is Zouzhuang mine. 
the problem that it was difficult to ensure the consistency of thinking when there were many evaluation indexes in a certain level in AHP. The primary object of this study was to provide a good reference value for the better management and protection of groundwater resources in mining area.

\section{Material and Methods}

\section{Study Site}

The Sulin mining area is a typical coal production base in Northern Anhui Province, China. It covers a total area of about 1000 square kilometers, with $33^{\circ} 20^{\prime}$ to $33^{\circ} 42^{\prime} \mathrm{N}$ and $116^{\circ} 15^{\prime}$ to $117^{\circ} 12^{\prime} \mathrm{E}$. Overall, it has convenient transportation, superior location, and rich coal resources. There are nineteen coal mines in this coal-mining district (Fig. 1). The study area has four distinct seasons and a suitable monsoon climate with an average annual temperature of $14.60^{\circ} \mathrm{C}$. The average annual rainfall and evaporation are $867 \mathrm{~mm}$ and $832.4 \mathrm{~mm}$, respectively, which are mainly concentrated in the summer.

The Sulin coal-mining district is all concealed deposits under the quaternary and Neogene loose beds in the Cenozoic Era $[13,14]$. Base on the Huaibei coalfield integrated hydrogeological histogram, the Cenozoic group contains four aquifers from top to bottom [15], namely, the first aquifer with a mean thickness of $33.27 \mathrm{~m}$, the second aquifer with a mean thickness of $35.43 \mathrm{~m}$, the third aquifer with a mean thickness of $60.76 \mathrm{~m}$, and the fourth aquifer with a mean thickness of $51.97 \mathrm{~m}$. The SG of in the Sulin coal-mining district is generally taken from the first aquifer, while $\mathrm{MG}$ is taken from the second and third aquifers, which are the main water source for drinking, agriculture, and industrial purpose in the study area.

\section{Sampling and Testing}

On the basis of preliminary field investigation, 34 SG samples and $18 \mathrm{MG}$ samples were respectively collected domestic wells, and water source wells from the entire coal-mining district in the summer of 2017. Before sampling, 2.5 L polyethylene bottles were rinsed three times with deionized water in the laboratory. At the same time, a potable GPS locator was prepared for simultaneously recording the coordinates (including longitudes and latitudes) of each sampling site. During field sampling, the bottles were washed three times with sample water before the samples were poured into it. In addition, the temperature, $\mathrm{pH}$ and total dissolved solids (TDS) of each sample were tested on site by using portable instruments (ST 20 AND ST20T-B) from OHAUS (Shanghai, China). All samples were transferred to the laboratory and stored at $4^{\circ} \mathrm{C}$ for further testing within 24 hours.
Experimental processes were carried out in the National Engineering Research Center of Coal Mine Water Hazard Controlling, China. The concentrations of $\mathrm{HCO}_{3}{ }^{-}$and $\mathrm{CO}_{3}{ }^{2-}$ were measured by using acid-base titration. The concentrations of $\mathrm{Na}^{+}, \mathrm{Ca}^{2+}, \mathrm{Mg}^{2+}, \mathrm{F}^{-}$, $\mathrm{Cl}^{-}, \mathrm{NO}_{3}^{-}$, and $\mathrm{SO}_{4}^{2-}$ of each groundwater sample were measured by an ion chromatograph (ICS-600-900). Heavy metals concentrations were determined by an inductively couples plasma mass spectrometry (ICPMS) (Agilent 7500cx), the concentrations of Cr, Mn, Ni, $\mathrm{Cu}, \mathrm{Zn}, \mathrm{Cd}$, and $\mathrm{Pb}$ were higher than the detection limit, while the other heavy metal (e.g. As, $\mathrm{Hg}$ ) contents were lower than the detection limit. In order to check the accuracy of instrumental analysis, blanks, duplicates, technical specifications for environmental monitoring of groundwater (HJ/T 164-2004) were employed. In addition, the relative percentage differences of the experimental data remained below $5 \%$.

\section{Research Methods}

Application of fuzzy AHP in water quality assessment is based on the following steps:

Step 1: Establish hierarchy mode

Establish a hierarchy structure of water quality assessment based on AHP method, this structure was subdivided into the target, criteria, and scheme layer [16]. This paper selected groundwater quality assessment as the target layer. Consideration of accuracy of evaluation results, we selected pollution factors as the criteria layer elements to establish evaluation factor set (U), namely, $\mathrm{U}=$ \{evaluation factors\}; According to the Chinese Quality Standard for Groundwater [17], this paper selected five evaluation levels as the scheme layer elements to establish evaluation criteria set (S), namely, $\mathrm{S}=\{\mathrm{I}, \mathrm{II}, \mathrm{III}, \mathrm{IV}$, and V $\}$.

Step 2: Build fuzzy evaluation matrix

Fuzzy membership values are considered as the probability that one indicator belongs to some grades. The common fuzzy membership function is semitrapezoidal [18], which is expressed as follows:

Class I:

$$
r_{i 1}=\left\{\begin{array}{l}
1,\left(C_{i} \leq S_{i 1}\right) \\
\frac{S_{i 2}-C_{i}}{S_{i 2}-S_{i 1}},\left(S_{i 1}<C_{i}<S_{i 2}\right) \\
0,\left(C_{i} \geq S_{i 2}\right)
\end{array}\right.
$$

Class II to Class IV:

$$
r_{i j}=\left\{\begin{array}{l}
\frac{C_{i}-S_{i j-1}}{S_{i j}-S_{i j-1}},\left(S_{i j-1}<C_{i}<S_{i j}\right) \\
0,\left(C_{i} \leq S_{i j-1} \text { or } C_{i} \geq S_{i j+1}\right) \\
\frac{S_{i j+1}-C_{i}}{S_{i j+1}-S_{i j}},\left(S_{i j}<C_{i}<S_{i j+1}\right)
\end{array}\right.
$$


Class V:

$$
r_{i n}=\left\{\begin{array}{l}
1,\left(C_{i} \geq S_{i n}\right) \\
\frac{S_{i 2}-C_{i}}{S_{i 2}-S_{i 1}},\left(S_{i n-1}<C_{i}<S_{i n}\right) \\
0,\left(C_{i} \leq S_{i n-1}\right)
\end{array}\right.
$$

...where $C_{i}$ and $S_{i j}$ are the measured values of indicator $i$ and standard values of indicator $i$ to class $j$, respectively. $r_{i j}$ is the membership degree of the evaluation factor $i$ to water quality level $j$.

The fuzzy evaluation matrix $R$ can be obtained when every evaluation factor had been calculated based on the fuzzy membership function established above.

Step 3: Determine evaluation factor's weight

The importance of each factor can be measured by weight, and AHP is an effective method to determine the weight [19]. Firstly, constructing a judgment matrix by the pair-wise relative importance of elements which is assigned an integer in the 1 to 9 based on the 1-9 scales by Saaty T. L. [20]. The scale value meaning is shown in Table 1. Besides, 2, 4, 6, 8 stand for the average value between two adjacent scales. Besides, if the importance is converse, the scale can be set as its reciprocal.

Secondly, checking the consistency of the judgment matrix to prevent the interference of other factors to the matrix by using the following formula.

$$
\begin{gathered}
C I=\left(\lambda_{\max }-n\right) /(n-1) \\
C R=C I / R I
\end{gathered}
$$

...where $C I$ is the consistency index; $\lambda_{\max }$ stands for the maximum eigenvalue of the judgment matrix; $n$ is the row number of the judgment matrix; $C R$ and $R I$ are the consistency ratio and random consistency index, respectively. $R I$ values of the judgment matrix of order 1-9 are shown in the literature [21].

If $C R$ is less than 0.1, the constructed judgment matrix meets the consistency. In this case, the eigenvalue vector of the judgment matrix is regarded as the weight vector $(W)$ of evaluation factors.

Step 4: Fuzzy AHP comprehensive assessment

The fuzzy comprehensive evaluation of subset $Y$ can be calculated from the fuzzy evaluation matrix $R$ and weight vector $W$ obtained above, namely:

Table 1. The scale and meaning of matrix judgment.

\begin{tabular}{|c|c|}
\hline Scale value & Meaning \\
\hline Equally important & 1 \\
\hline Slight important & 3 \\
\hline Obviously important & 5 \\
\hline Strongly important & 7 \\
\hline Extremely important & 9 \\
\hline
\end{tabular}

$$
Y=R \cdot W
$$

Finally, this paper judged the grade of evaluation result according to the principle of maximum membership degree. The highest grade is the water quality level of the sample.

\section{Results and Discussion}

\section{Hydrochemical Characteristics}

Characterization of the hydrochemical properties of $\mathrm{SG}$ and $\mathrm{MG}$ in the Sulin coal-mining district (Table 2), which was useful to get a view of the conventional components of SG and MG in the study area.

\section{pH and TDS}

The chemistry of SG and MG showed that their $\mathrm{pH}$ values were within the range $(6.5-8.5)$ set by the Chinese Quality Standard for Groundwater, indicating their neutral nature. However, the variation range of $\mathrm{pH}$ value for SG was obviously large, and its CV was $0.94 \%$ higher than that of MG. It could be inferred that SG was closely related to the supergene environment, while the $\mathrm{pH}$ values of MG was relatively stable. Under normal circumstances, MG was less disturbed by SG or the supergene environment.

The total dissolved solids (TDS) was also an important indicator for judging water quality. According to the Chinese Quality Standard for Groundwater, 28.12\% SG samples and 38.89\% MG samples had TDS values above the thresholds of class III. Obviously, the variation range of TDS in SG was larger than that in MG, which also showed that SG was greatly affected by the supergene environment. The spatial distribution of TDS in SG and MG of the study area was shown in Fig. 2 and Fig. 3. The low levels of TDS for SG were detected in Northwest and Southeast of the study area, while that in the other places were relatively high. The TDS of MG increased gradually from Southeast to Northeast, indicating that MG had a trend of migration from Southeast to Northwest. Therefore, there were obvious differences in the trend of TDS in SG and MG.

\section{Ion Chemistry}

The variations in the major ion concentrations were illustrated in Table 2. The relative abundance of major cations and anions for $\mathrm{SG}$ were as follows: $\mathrm{Na}^{+}>\mathrm{Ca}^{2+}>\mathrm{Mg}^{2+}$ and $\mathrm{HCO}_{3}^{-}>\mathrm{SO}_{4}{ }^{2-}>\mathrm{Cl}^{-}$, respectively, which was result of supergene environment impact. While for MG, the relative abundance of major cations and anions were as follows: $\mathrm{Na}^{+}>\mathrm{Mg}^{2+}>\mathrm{Ca}^{2+}$ and $\mathrm{HCO}_{3}^{-}$ $>\mathrm{SO}_{4}{ }^{2-}>\mathrm{Cl}^{-}$, respectively. In addition, $\mathrm{Na}^{+}$and $\mathrm{HCO}_{3}^{-}$ were dominant ions in both $\mathrm{SG}$ and $\mathrm{MG}$. As a result 
Table 2. Statistical characteristics of conventional hydrochemical component.

\begin{tabular}{|c|c|c|c|c|c|c|c|c|c|c|}
\hline \multirow{2}{*}{ Item } & \multicolumn{9}{|c|}{ SG } & \multicolumn{4}{c|}{ MG } \\
\cline { 2 - 13 } & Min & Max & Mean & SD & CV(\%) & Min & Max & Mean & SD & CV(\%) \\
\hline $\mathrm{Na}^{+}$ & 20.32 & 426.19 & 135.65 & 105.09 & 77.48 & 49.56 & 425.69 & 200.91 & 94.15 & 46.86 \\
\hline $\mathrm{Ca}^{2+}$ & 18.22 & 206.12 & 74.95 & 52.63 & 70.22 & 20.20 & 76.01 & 41.54 & 15.58 & 37.51 \\
\hline $\mathrm{Mg}^{2+}$ & 19.04 & 178.04 & 65.52 & 36.79 & 56.15 & 27.69 & 91.10 & 47.66 & 15.86 & 33.28 \\
\hline $\mathrm{F}^{-}$ & 0.00 & 0.92 & 0.03 & 0.16 & 502.86 & 0.44 & 2.06 & 1.12 & 0.45 & 39.94 \\
\hline $\mathrm{Cl}^{-}$ & 4.33 & 362.81 & 124.02 & 99.66 & 80.36 & 18.13 & 300.50 & 97.96 & 70.23 & 71.69 \\
\hline $\mathrm{NO}_{3}^{-}$ & 0.00 & 420.50 & 45.90 & 95.09 & 207.16 & 0.00 & 8.51 & 1.48 & 2.67 & 179.65 \\
\hline $\mathrm{SO}_{4}^{2-}$ & 1.89 & 1033.36 & 174.61 & 205.42 & 117.65 & 40.04 & 604.82 & 229.44 & 169.79 & 74.00 \\
\hline $\mathrm{HCO}_{3}^{-}$ & 267.62 & 873.19 & 487.82 & 158.24 & 32.44 & 377.09 & 853.02 & 560.60 & 124.86 & 22.27 \\
\hline $\mathrm{CO}_{3}^{2-}$ & 0.00 & 0.00 & 0.00 & 0.00 & 0.00 & 0.00 & 14.40 & 3.47 & 5.93 & 171.09 \\
\hline $\mathrm{pH}^{2-}$ & 6.55 & 7.80 & 7.12 & 0.24 & 3.36 & 7.04 & 7.76 & 7.29 & 0.18 & 2.42 \\
\hline $\mathrm{TDS}^{-}$ & 287.86 & 1879.16 & 818.65 & 394.19 & 48.15 & 437.00 & 1864.78 & 904.94 & 365.42 & 40.38 \\
\hline
\end{tabular}

Notes: Unit-(mg/L); SD indicates standard deviation, CV indicates coefficient of variation

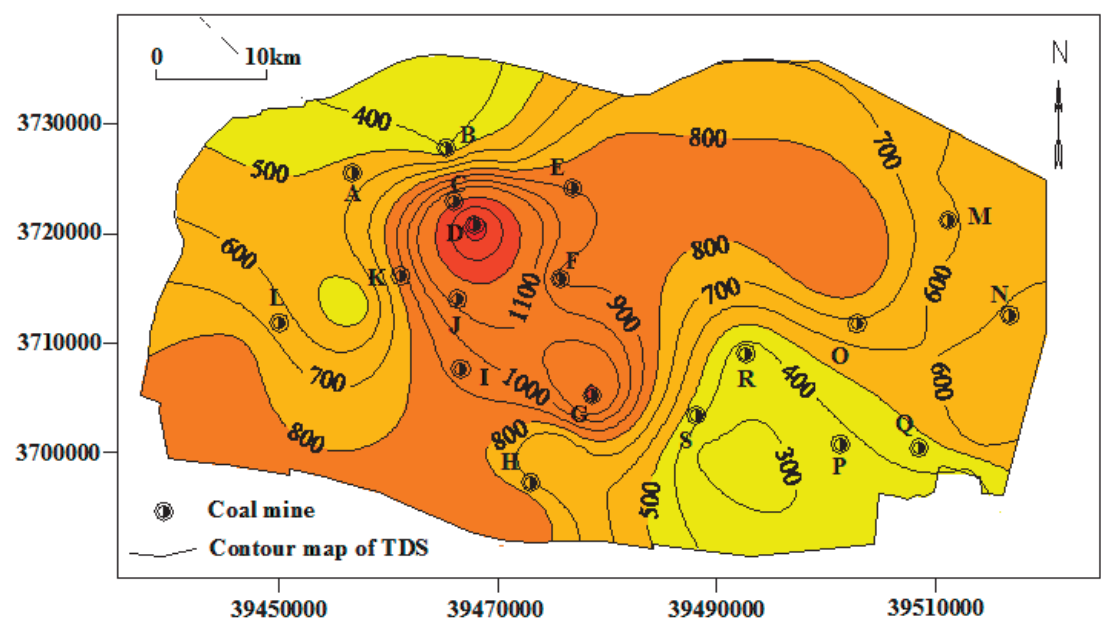

Fig. 2. Contour map of TDS (mg/L) for SG in the study area.

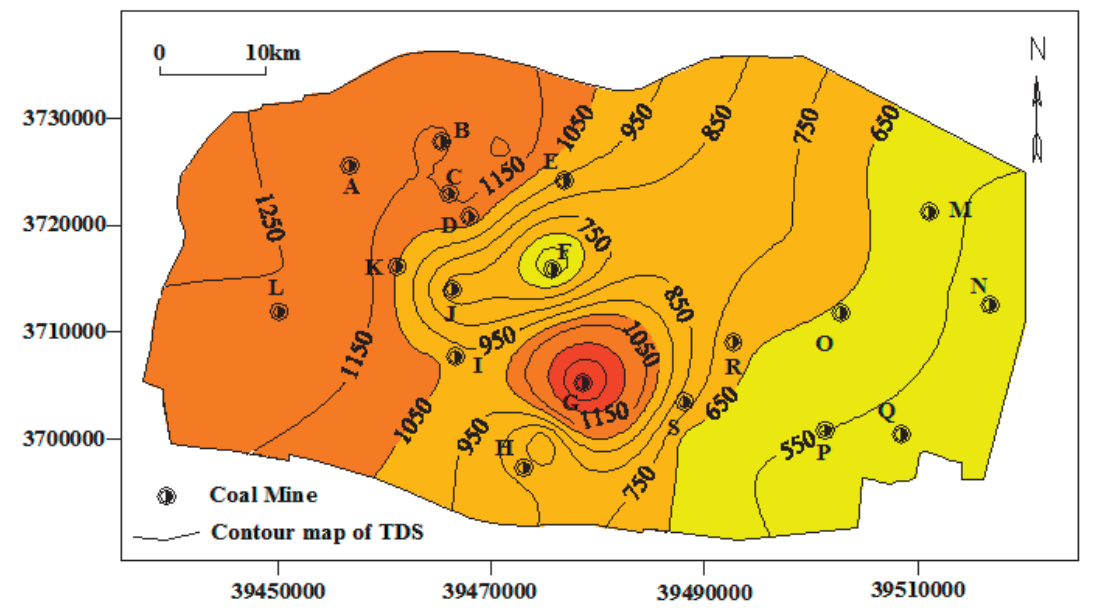

Fig. 3. Contour map of TDS (mg/L) for MG in the study area. 
Table 3. Statistics of heavy metals concentrations for groundwater in the study area.

\begin{tabular}{|c|c|c|c|c|c|c|c|c|c|c|}
\hline \multirow{2}{*}{ Item } & \multicolumn{5}{|c|}{$\mathrm{SG}$} & \multicolumn{5}{|c|}{ MG } \\
\hline & Min & Max & Mean & SD & $\mathrm{CV}(\%)$ & Min & Max & Mean & SD & $\mathrm{CV}(\%)$ \\
\hline $\mathrm{Cr}$ & 0.02 & 1.54 & 0.08 & 0.27 & 319.28 & 0.02 & 0.59 & 0.21 & 0.15 & 71.11 \\
\hline $\mathrm{Mn}$ & 0.03 & 564.57 & 78.87 & 118.01 & 149.63 & 20.72 & 256.80 & 119.69 & 67.12 & 56.08 \\
\hline $\mathrm{Ni}$ & 0.01 & 0.85 & 0.20 & 0.20 & 101.81 & 0.72 & 2.28 & 1.21 & 0.46 & 38.11 \\
\hline $\mathrm{Cu}$ & 0.01 & 0.32 & 0.08 & 0.08 & 104.32 & 0.00 & 0.73 & 0.10 & 0.18 & 191.04 \\
\hline $\mathrm{Zn}$ & 0.00 & 2.30 & 0.27 & 0.63 & 230.85 & 0.13 & 37.22 & 8.07 & 9.98 & 123.73 \\
\hline $\mathrm{Sr}$ & 512.39 & 3197.73 & 1511.46 & 669.88 & 44.32 & 726.00 & 2691.00 & 1317.43 & 560.98 & 42.58 \\
\hline $\mathrm{Cd}$ & 0.00 & 0.06 & 0.03 & 0.02 & 68.67 & 0.01 & 0.07 & 0.02 & 0.01 & 66.52 \\
\hline $\mathrm{Pb}$ & 0.00 & 0.05 & 0.01 & 0.01 & 105.76 & 0.00 & 0.05 & 0.01 & 0.01 & 75.69 \\
\hline
\end{tabular}

Notes: Unit-(ug/L); SD indicates standard deviation, CV indicates coefficient of variation

of large scale pumping, the MG was in a relatively open environment. In addition, side supply of hillside rainwater resulted in a large amount of $\mathrm{CO}_{2}$ gas in the atmosphere would dissolve into MG, ultimately, forming bicarbonate water similar to SG. Compared with the threshold for class III, $18.75 \%, 9.38 \%$, and $21.8 \%$ of SG samples had concentration of $\mathrm{SO}_{4}{ }^{2-}, \mathrm{Cl}^{-}$, and $\mathrm{Na}^{+}$ more than the standard values. While for MG, $38.89 \%$, $5.56 \%$, and $50.00 \%$ of samples had concentration of $\mathrm{SO}_{4}^{2-}, \mathrm{Cl}^{-}$, and $\mathrm{Na}^{+}$higher than the standard values.

The fluoride contents for SG was lower than the class III limit $(1.0 \mathrm{mg} / \mathrm{L})$, while for $\mathrm{MG}, 55.56 \%$ of samples had fluoride contents above the limit. As it was previously reported by $\mathrm{Wu}$ [22], excessive fluoride might be related to the high fluorine waste discharge site such as coal mines and power plants. However, our results showed that the fluoride concentration in SG of the study area was relatively low, while that in MG was relatively high, which indicated that the source of fluoride in MG was not related to the high fluorine waste discharge, likely because of geological reasons. The $\mathrm{NO}_{3}{ }^{-}$concentrations of $\mathrm{MG}$ were lower than the class III limit value $(\leq 20.0 \mathrm{mg} / \mathrm{L})$ of Chinese groundwater standards and Chinese drinking water standard of $20.0 \mathrm{mg} / \mathrm{L}$, while for $\mathrm{SG}, 37.50 \%$ SG samples had $\mathrm{NO}_{3}{ }^{-}$ contents above the limit, indicating that $\mathrm{SG}$ of the study area was seriously polluted by $\mathrm{NO}_{3}^{-}$. According to the field investigation, the SG sample of $\mathrm{H}$ coal mine was collected from a domestic well with a depth of 6-7 m, which was close to a pig farm. It could be inferred that the infiltration of leachate from the pig farm might result in the high levels of $\mathrm{NO}_{3}^{-}$in this coal mine.

\section{Heavy Metal Chemisty}

The summary statistics for SG and MG samples in the study area were presented in Table 3 . The mean concentrations of heavy metals for SG and MG samples in the study area in a decreasing order as: $\mathrm{Mn}>\mathrm{Zn}>$ $\mathrm{Ni}>\mathrm{Cr}=\mathrm{Cu}>\mathrm{Cd}>\mathrm{Pb}$, and $\mathrm{Mn}>\mathrm{Zn}>\mathrm{Ni}>\mathrm{Cr}>\mathrm{Cu}>\mathrm{Cd}=\mathrm{Pb}$, respectively. The concentrations of $\mathrm{Mn}$ and $\mathrm{Zn}$ in SG and MG samples were highest, which were consistent with the previous studies [15]. Using the Chinese groundwater standards and drinking water standards of the World Health Organization (WHO) [23] as a reference, the $\mathrm{Mn}$ concentrations in nine SG samples and $11 \mathrm{MG}$ samples exceeded the threshold of class III (100 ug/L), and contributed $28.13 \%$ and $61.11 \%$, respectively, while the other heavy metals concentration were relatively low. The high concentration of $\mathrm{Mn}$ might be related to the unique geomorphology and reduction environment in the Sulin coal-mining district.

\section{Hydrogeochemical Processes}

Hydrochemical processes and formation mechanisms of SG and MG in the Sulin coal-mining district can be understood by using molar ratios of major ions [24]. The $\mathrm{Ca}^{2+}$ vs. $\mathrm{Na}^{+}$and $\mathrm{Mg}^{2+}$ vs. $\mathrm{Na}^{+}, \mathrm{Ca}^{2+}$ vs. $\mathrm{Na}^{+}$and $\mathrm{Ca}^{2+}$ vs. $\mathrm{HCO}_{3}^{-}$(Fig. 4) can reflect the effects of waterrock interactions [25]. It can be seen from Fig. 4 that the geochemical composition of SG and MG was mainly determined by the dissolution of silicates. The strata in this area are mainly composed of weathered clastic rocks dominated by silicate minerals, implying that the contribution of silicate was dominant in that area.

The dissolution of halite $(\mathrm{NaCl})$ in water releases roughly equal concentrations of sodium ion and chloride ion. However, most of $\mathrm{Cl}^{-}$and $\mathrm{Na}^{+}$vs. $\mathrm{Cl}^{-}$ratios for SG and MG samples (Fig. 5a) were greater than 1, suggesting that the dissolution of halite in groundwater was not the only source of $\mathrm{Na}^{+}$. To understand another source of $\mathrm{Na}^{+}$, this paper computed $\mathrm{Ca}^{2+}$ and $\mathrm{Mg}^{2+}$ vs. $\mathrm{SO}_{4}^{2-}$ and $\mathrm{HCO}_{3}^{-}$ratios (Fig. 5b). The figure showed that most of $\mathrm{SG}$ samples and MG samples distributed above 1:1 trend line, which indicated that excess cations exist to participate in the reaction of $\mathrm{SO}_{4}^{2-}$ and $\mathrm{HCO}_{3}$. Combined with the regional formation lithology, it was speculated that the excess cations might come from $\mathrm{Na}^{+}$in the weathered clastic rock 

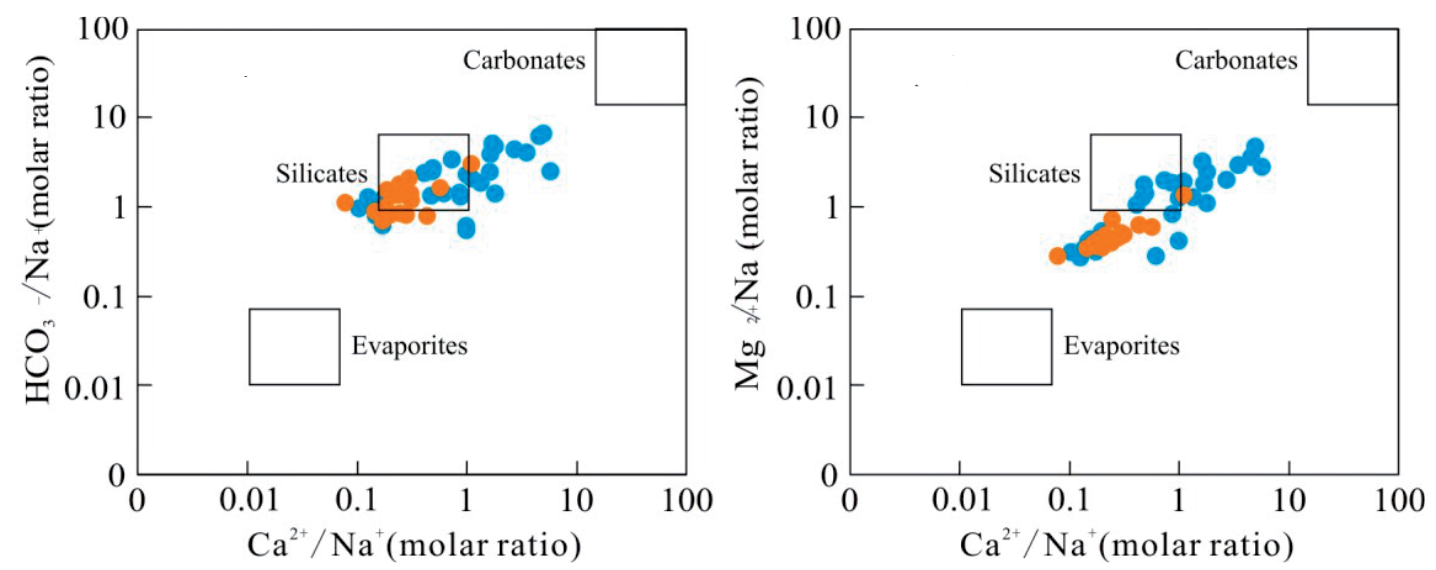

Fig. 4. Source distribution of samples by composition ratios. a) $\mathrm{HCO}_{3}^{-} / \mathrm{Na}^{+} \mathrm{vs} . \mathrm{Ca}^{2+} / \mathrm{Na}^{+}$, b) $\mathrm{Mg}^{2+} / \mathrm{Na}^{+} \mathrm{vs} . \mathrm{Ca}^{2+} / \mathrm{Na}^{+}$.

mainly composed of silicate minerals [26]. In addition, $\left(\mathrm{Ca}^{2+}+\mathrm{Mg}^{2+}-\mathrm{SO}_{4}^{2-}-\mathrm{HCO}_{3}^{-}\right) /\left(\mathrm{Na}^{+}-\mathrm{Cl}^{-}\right)$ratios (Fig. 5c) can be used to characterize the degree of ion exchange. Fig. 5c) showed that most of $\mathrm{SG}$ and $\mathrm{MG}$ samples were close to the 1:1 trend line and their linear correlation coefficients were 0.95 and 0.93 , respectively, indicating that the major ion components of SG and MG were greatly affected by ion exchange, which proved that the extra $\mathrm{Na}^{+}$participated in water-rock interaction. The sources $\mathrm{Ca}^{2+}$ and $\mathrm{Mg}^{2+}$ in groundwater are usually judged by a ratio of $\mathrm{Ca}^{2+}$ and $\mathrm{Mg}^{2+}$ vs. $\mathrm{HCO}_{3}^{-}$[27]. If $\mathrm{Ca}^{2+}$ and $\mathrm{Mg}^{2+}$ originate from carbonate, the ratio will be 1:2. However, some SG samples and $\mathrm{MG}$ samples had a ratio above 1:2 (Fig. 5d), which suggested that the carbonate dissolution was not the main source of $\mathrm{Ca}^{2+}$ and $\mathrm{Mg}^{2+}$. Besides, Fig. 5e) showed that $\mathrm{Ca}^{2+}$ and $\mathrm{Mg}^{2+}$ had a good correlation with $\mathrm{Cl}^{-}$, evaporate dissolution might be another important source of $\mathrm{Ca}^{2+}$ and $\mathrm{Mg}^{2+}$.

\section{Groundwater Quality Assessment Based on Fuzzy AHP}

According to the above-mentioned analytical results of the groundwater pollution situation in the study area, the evaluation factors of SG and MG were TDS, $\mathrm{SO}_{4}^{2-}, \mathrm{Cl}^{-}, \mathrm{Mn}, \mathrm{Na}^{+}$, and $\mathrm{NO}_{3}^{-} ; \mathrm{TDS}, \mathrm{SO}_{4}^{2-}, \mathrm{Cl}^{-}, \mathrm{Mn}$, $\mathrm{Na}^{+}$and $\mathrm{F}^{-}$, respectively, namely, USG $=\left\{\mathrm{TDS}, \mathrm{SO}_{4}^{2-}\right.$, $\mathrm{Cl}^{-}, \mathrm{Mn}, \mathrm{Na}^{+}$and $\left.\mathrm{NO}_{3}^{-}\right\}$, and $\mathrm{UMG}=\left\{\mathrm{TDS}, \mathrm{SO}_{4}^{2-}, \mathrm{Cl}^{-}\right.$, $\mathrm{Mn}, \mathrm{Na}^{+}$and $\left.\mathrm{F}^{-}\right\}$. Using the Chinese Quality Standard for Groundwater as a reference, this study selected five evaluation levels as the evaluation set, namely, $\mathrm{S}=\{\mathrm{I}, \mathrm{II}, \mathrm{III}, \mathrm{IV}$, and V $\}$. Based on the established groundwater quality assessment system, we denoted U as the criteria layer, and $\mathrm{S}$ as scheme layer. Hierarchical structure model of groundwater quality assessment for SG and MG was displayed in Fig. 6.

According to the water quality classification standard, combined with the selected evaluation factors of SG and MG, fuzzy evaluation matrix of SG and $M G$ were obtained according to Equations (1)-(3) as follows:

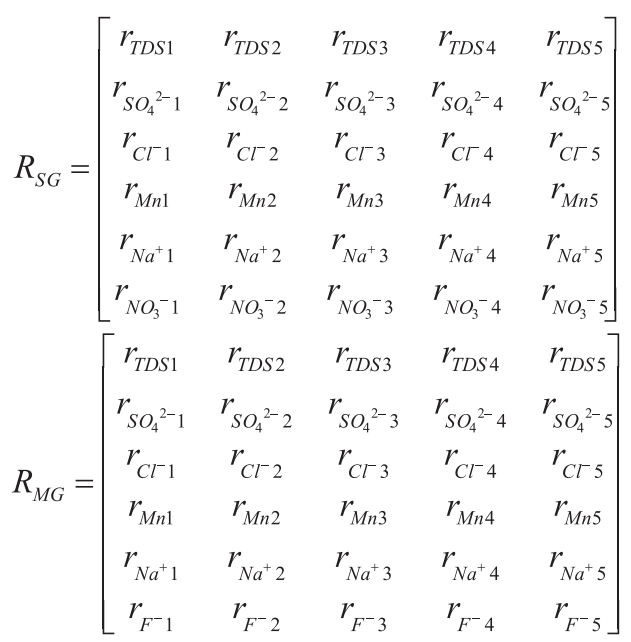

On the basis of the mentioned Saaty TL 1-9 scale method and the degree of the evaluation factors influence on water quality, this paper constructed the judgment matrix of $\mathrm{SG}$ and $\mathrm{MG}$ by assigning a value for each evaluation factor according to the result of export scoring to the pair-wise relative importance of evaluation factors, then checked the consistency of judgment matrix by the Equations (4)-(5). The judgment matrix of SG and $\mathrm{MG}\left(A_{S G}\right.$ and $A_{M G}$ ) passing the consistency test were as follows.

$$
\begin{aligned}
& A_{S G}=\left[\begin{array}{cccccc|c}
1 & 2 & 5 & 6 & 3 & 7 & \mathrm{TDS} \\
1 / 2 & 1 & 4 & 5 & 2 & 7 & \mathrm{SO}_{4}{ }^{2-} \\
1 / 5 & 1 / 4 & 1 & 2 & 1 / 3 & 3 & \mathrm{Cl}^{-} \\
1 / 6 & 1 / 5 & 1 / 2 & 1 & 1 / 5 & 2 & \mathrm{Mn}^{-} \\
1 / 3 & 1 / 2 & 3 & 5 & 1 & 5 & \mathrm{NO}_{3}^{-} \\
1 / 7 & 1 / 7 & 1 / 3 & 1 / 2 & 1 / 5 & 1
\end{array}\right] \mathrm{Na}^{+}
\end{aligned}
$$

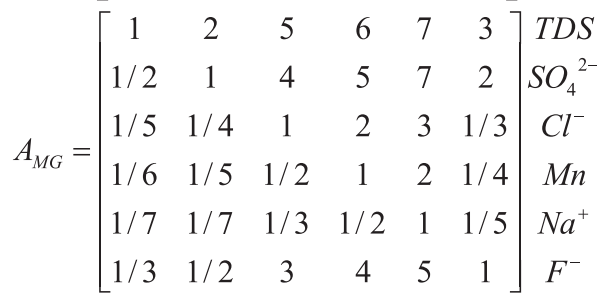



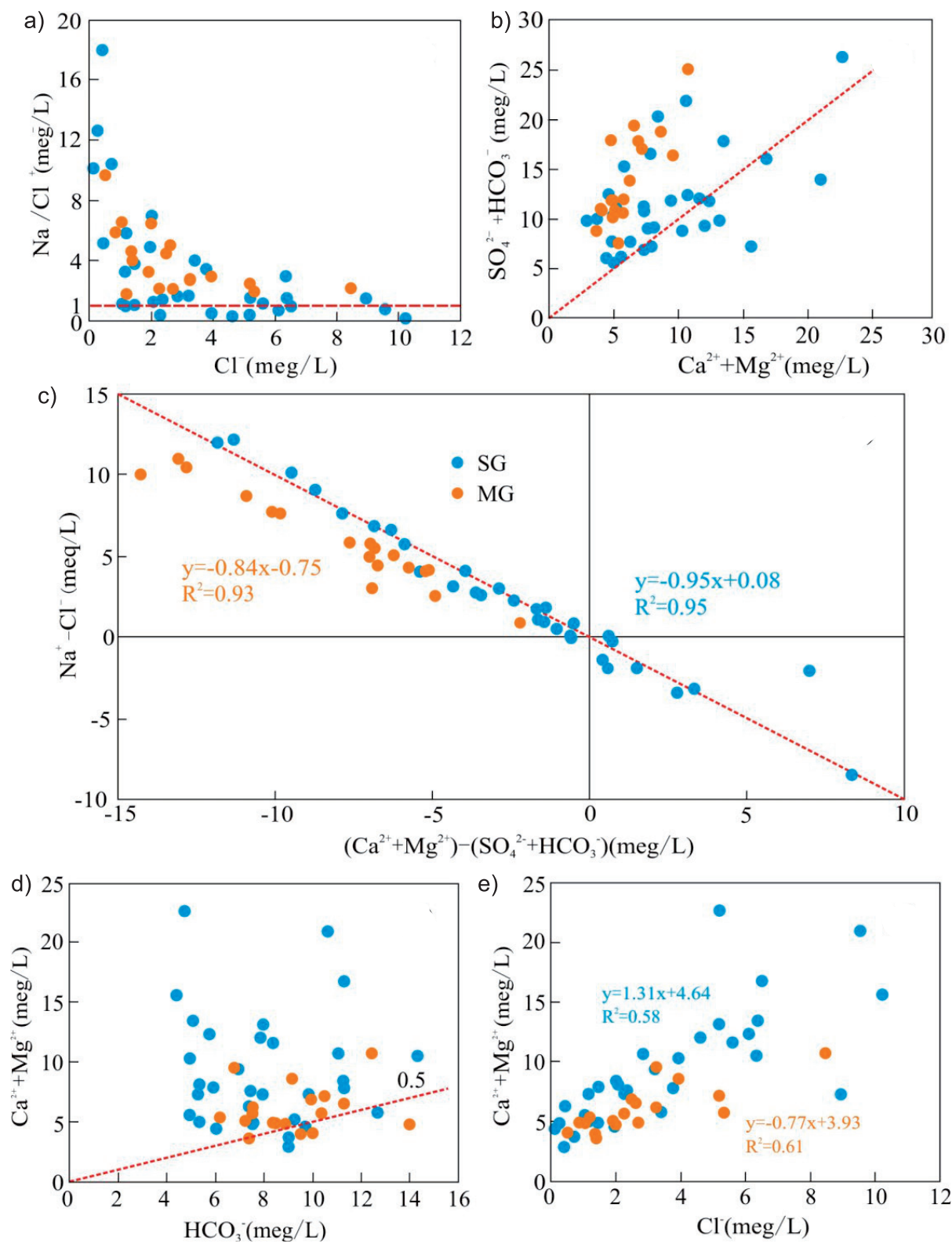

Fig. 5. Scatter plots of $\mathrm{SG}$ and $\mathrm{MG}$ in the study area.a) $\mathrm{Na}^{+} / \mathrm{Cl}^{-}$vs. $\mathrm{Cl}-$ b) $\left(\mathrm{SO}_{4}^{2-}+\mathrm{HCO}_{3}^{-}\right)$vs. $\left(\mathrm{Ca}^{2+}+\mathrm{Mg}^{2+}\right)$, c) $\left(\mathrm{Na}^{+}-\mathrm{Cl}^{-}\right)$vs. $\left(\mathrm{Ca}^{2+}+\right.$ $\left.\mathrm{Mg}^{2+}-\mathrm{SO}_{4}^{2-}+\mathrm{HCO}_{3}^{-}\right)$, d) $\left(\mathrm{Ca}^{2+}+\mathrm{Mg}^{2+}\right)$ vs. $\left.\mathrm{HCO}_{3}^{-}, \mathrm{e}\right)\left(\mathrm{Ca}^{2+}+\mathrm{Mg}^{2+}\right)$ vs. $\mathrm{Cl}^{-}$.

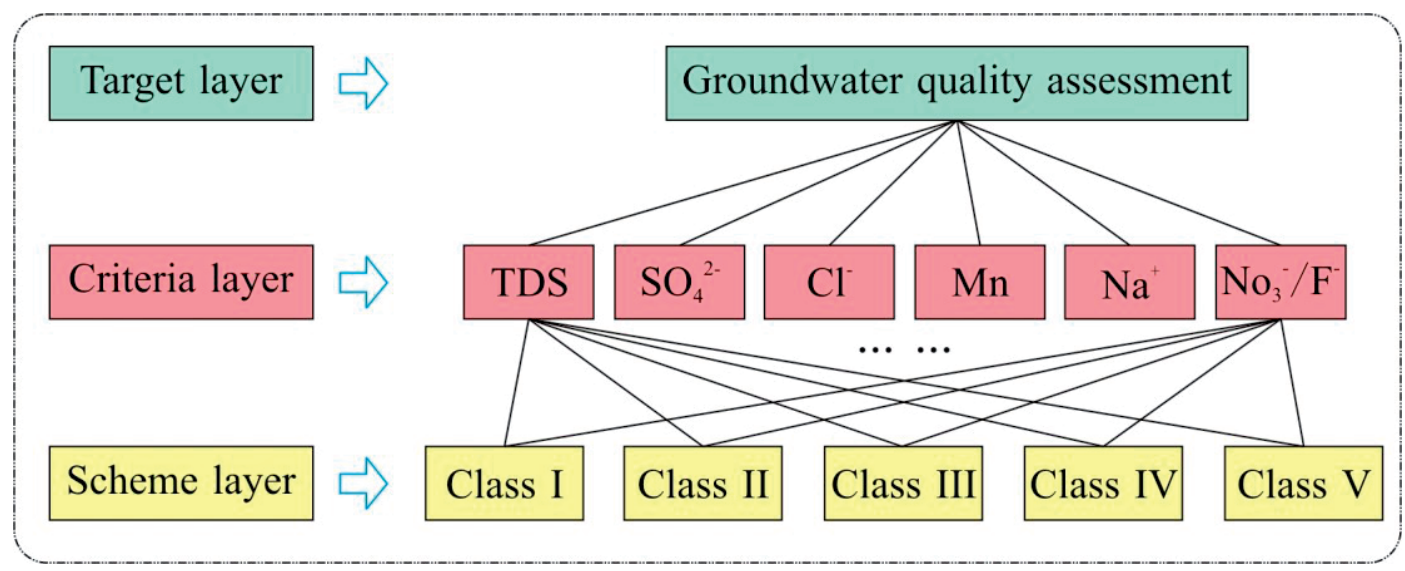

Fig. 6. Hierarchical structure model of groundwater quality in the study area. 
With the help of MATLAB software, we calculated the eigenvalue and eigenvalue vector of $A_{S G}$ and $A_{M G}$, and took the maximum eigenvalue vector as the weight vectors of evaluation factors. $W_{S G}$ and $W_{M G}$ were the normalized eigenvalue vector corresponding to the maximum eigenvalue $\lambda_{\max }=6.1769$ and $\lambda_{\max }=6.1064$, respectively.

$$
\begin{aligned}
& W_{S G}=(0.3898,0.2651,0.0794,0.0509,0.1798,0.0350)^{T} \\
& W_{M G}=(0.3930,0.2672,0.0824,0.0489,0.0354,0.1732)^{T}
\end{aligned}
$$

Therefore, the weights of evaluation factors (TDS, $\mathrm{SO}_{4}^{2-}, \mathrm{Cl}^{-}, \mathrm{Mn}, \mathrm{Na}^{+}$, and $\mathrm{F}^{-}$) for $\mathrm{SG}$ were $0.3898,0.2651$, $0.0794,0.0509,0.1798$, and 0.0350 , and the weights of evaluation factors (TDS, $\mathrm{SO}_{4}^{2-}, \mathrm{Cl}^{-}, \mathrm{Mn}, \mathrm{NO}_{3}^{-}$, and $\mathrm{Na}^{+}$) for $\mathrm{MG}$ were $0.3930,0.2672,0.0824,0.0489,0.0354$, and 0.1732 .

According to $R$ and $W$ obtained above, the fuzzy comprehensive evaluation of $\mathrm{SG}$ and $\mathrm{MG}$ was carried out by the formula (6). Statistical analysis of evaluation results showed $28.13 \%, 28.13 \%, 34.38 \%$ of the total SG samples could be categorized into I, II, and III, respectively, whereas only $6.25 \%$ and $3.13 \%$ of the total SG samples were classified as IV and V respectively. Twenty-nine SG samples were suitable for drinking, contributing $90.64 \%$ of the total SG samples. Overall, our results showed that the water quality SG was good and suitable for drinking. The contributions of class I, II, and III were $16.67 \%, 38.89 \%$, and $38.89 \%$ of the total MG samples, respectively, while the MG samples excessed class III only had one and contributed 5.56\%. Seventeen MG samples were suitable for drinking, accounting for $94.44 \%$ of the total MG samples, indicating that mid-layer groundwater was suitable for drinking. The results of this study also showed that the samples of SG and MG within class III contributed $90.64 \%$ and $94.44 \%$, respectively, and no MG sample was grouped into class V. Therefore, the mid-layer groundwater quality was better than shallow groundwater in the study area.

Based on the above research results, we found that the water quality of SG and MG were consistent with the actual natural conditions of the study area and comprehensive quality evaluation results [12], which showed that the fuzzy AHP was applicable for water quality assessment and had certain rationality. In comparison with previous study results $[18,28]$, this method avoided the disadvantage that the evaluation result was greatly influenced by a certain evaluation factor and made full use of experts' experience. Besides, it could quantitatively consider the influence degree to water quality and weight about various evaluation factors. In conclusion, the fuzzy AHP method had good practicability and could be used for water quality evaluation work in other sites.

\section{Conclusions}

This study completed an analysis of hydrogeochemical characteristics and the water quality assessment for drinking purposes based on fuzzy AHP in the Sulin coal-mining district. The analytical results of the hydrogeochemical characteristics suggested that SG and MG were characterized by neutral nature, and their dominant ions were $\mathrm{Na}^{+}$and $\mathrm{HCO}_{3}^{-}$. Besides, the relative abundance of major cations and anions for SG were as follows: $\mathrm{Na}^{+}>\mathrm{Ca}^{2+}>\mathrm{Mg}^{2+}$ and $\mathrm{HCO}_{3}^{-}$ $>\mathrm{SO}_{4}{ }^{2-}>\mathrm{Cl}^{-}$, respectively, while the relative abundance of major cations and anions of $\mathrm{MG}$ were as follows: $\mathrm{Na}^{+}>\mathrm{Mg}^{2+}>\mathrm{Ca}^{2+}$ and $\mathrm{HCO}_{3}>\mathrm{SO}_{4}^{2-}>\mathrm{Cl}^{-}$, respectively. Based on analysis with molar ratios of major ions, the geochemical composition of SG and MG were mainly determined by the dissolution of silicates. Statistical analysis of fuzzy AHP evaluation results showed $9.38 \%$ of the total SG samples and $5.56 \%$ of the total MG samples excessed the warning limit groundwater pollution level. In conclusion, research revealed that most of the groundwater of the study area was good and could be used for drinking water. Besides, the fuzzy AHP method was feasible as well as had a good reference value and application prospect for evaluating water quality in other sites.

\section{Acknowledgements}

This research was funded by the National Natural Science Foundation of China, grant number 41773100 and 41373095; Natural Science Foundation of Anhui Province, grant number 2008085QD192, Key project of excellent talents support program in colleges and universities, grant number gxyqZD2020048, Doctoral research initiation fund project, grant number 2020BS010. The authors sincerely appreciate the manuscript handling Editor and anonymous reviewers for their valuable comments and suggestions to make the manuscript more worthy.

\section{Conflict of Interest}

The authors declare no conflict of interest.

\section{References}

1. NURTAZIN S., PUREPPKE S., OSPAN, T., MUKHITDINOV A., ELEBESSOV T. Quality of Drinking Water in the Balkhash District of Kazakhstan's Almaty Region. Water, 12, 392, 2020.

2. LIU J., JIN D.W., WANG T.T., GAO M., YANG J., WANG Q.M. Hydrogeochemical processes and quality assessment of shallow groundwater in Chenqi coalfield, Inner Mongolia, China. Environmental Earth Sciences, 78, 347, 2019. 